\title{
A língua de sinais na formação do profissional da área de ciências humanas e sociais aplicadas
}

The lenguage of signs in the training of the professional of the area of applied human and social sciences

La lengua de señales en la formación del profesional del área de ciencias humanas y sociales aplicadas

\section{* Weslley Kozlik Silva}

Doutorando na Universidade Federal do Paraná, Curitiba, Paraná, Brasil.

weskozlik@hotmail.com

\section{${ }^{* *}$ Pollyana Pittner}

Graduada pela Faculdade Guairacá, Guarapuava, Paraná, Brasil.

polly_pittner1@hotmail.com

Recebido: 19 de março de 2018

Aprovado: 16 de novembro de 2018

\section{RESUMO}

Um assunto importante que vem sendo discutido é a crescente necessidade de melhoria da formação de profissionais para atuar com pessoas com necessidades especiais, como condição essencial para uma adequada inclusão destas pessoas em todos os âmbitos da vida social. A surdez é uma das condições especiais com que o profissional da área das Ciências Humanas e Ciências Sociais Aplicadas pode se deparar em sua prática, e sabese que a forma de comunicação do surdo é por meio da Língua Brasileira de Sinais - Libras. Dessa forma, torna-se relevante pesquisar sobre como está ocorrendo a formação destes profissionais nos cursos de graduação e se os conteúdos referentes à surdez, especificamente com relação à Libras, são trabalhados. Para isso, objetivou-se analisar as disciplinas das grades curriculares de três cursos destas áreas buscando identificar estes aspectos. De acordo com os objetivos a que este trabalho se propôs, utilizou-se a metodologia de pesquisa documental, com caráter misto, ou seja, tanto qualitativa como quantitativa. Os resultados apontam que a maioria das instituições estudadas não incluem esta disciplina em seus currículos, ressaltando-se a importância de que as instituições de ensino superior realizem avaliações periódicas sobre seus projetos pedagógicos e estruturas formativas, buscando adequar seu ensino voltado às necessidades da sociedade atual, pois a presença de pessoas com necessidades especiais em todas as esferas da vida social é uma realidade para a qual não se pode mais fechar os olhos.

Palavras-chave: Formação de Profissionais; Ciências Humanas e Sociais Aplicadas; Libras. 


\section{ABSTRACT}

An important issue that has been discussed is the growing requirement to improve the training of professionals to work with people with special needs, as an essential condition for the adequate inclusion of these people in all areas of social life. Deafness is one of the special conditions that the professional in the field of Human Sciences and Applied Social Sciences can encounter in their practice, and it is known that the deaf person's communication is through Libras (Brazilian Sign Language). Therefore, it is relevant to research on how the training of these professionals is taking place in undergraduate courses and whether the contents related to deafness, specifically in relation to Libras, are developed. The purpose of this study was to analyze the curricular disciplines of three courses in these areas in order to identify these aspects. According to the objectives to which this work was proposed, the methodology of documentary research was used, with a mixed character, that is, both qualitative and quantitative. The results point out that most of the institutions studied do not include this discipline in their curricula, emphasizing the importance of higher education institutions conduct periodic evaluations of their pedagogical projects and formative structures, seeking to adapt their teaching focused on the current social needs, because the presence of people with special needs in all spheres of social life is a reality for which we cannot close our eyes.

Keywords: Professional Formation; Applied Human and Social Sciences; Pounds.

\section{RESUMEN}

Un tema importante que viene siendo discutido es la creciente necesidad de mejora de la formación de profesionales para actuar con personas con necesidades especiales, como condición esencial para una adecuada inclusión de estas personas en todos los ámbitos de la vida social. La sordera es una de las condiciones especiales con que el profesional del área de las Ciencias Humanas y Ciencias Sociales Aplicadas puede encontrarse en su práctica, y se sabe que la forma de comunicación del sordo es por medio de la Lengua Brasileña de Señales - Libras. De esta forma, parece relevante investigar sobre cómo está ocurriendo la formación de estos profesionales en los cursos de graduación y si los contenidos referentes a la sordera, específicamente con relación a la Libras, son trabajados. Para ello, se objetivó analizar las disciplinas de las cuadrículas curriculares de tres cursos de estas áreas buscando identificar estos aspectos. De acuerdo con los objetivos a que este trabajo se propuso, se utilizó la metodología de investigación documental, con carácter mixto, o sea, tanto cualitativa como cuantitativa. Los resultados apuntan que la mayoría de las instituciones estudiadas no incluyen esta disciplina en sus currículos, resaltando la importancia de que las instituciones de enseñanza superior realicen evaluaciones periódicas sobre sus proyectos pedagógicos y estructuras formativas, buscando adecuar su enseñanza hacia las necesidades de la sociedad actual porque la presencia de personas con necesidades especiales en todas las esferas de la vida social es una realidad que ya no se puede cerrar los ojos.

Palabras clave: Formación de Profesionales; Ciencias Humanas y Sociales Aplicadas; Libras. 


\section{Introdução}

Um assunto importante que tem sido discutido é a crescente necessidade de melhoria da formação de profissionais para atuar com pessoas com necessidades especiais, como condição essencial para uma adequada inclusão destas pessoas em todos os âmbitos da vida social. A surdez é uma das condições especiais com que o profissional da área das Ciências Humanas e da área das Ciências Sociais Aplicadas pode se deparar em sua prática, e sabe-se que a forma de comunicação do surdo é por meio da Língua Brasileira de Sinais - Libras, necessitando, assim, que nos espaços sociais hajam profissionais capacitados a atender de maneira adequada e oferecer atenção especial às pessoas com surdez. Para isso, um ensino que aborde essa temática enquanto o profissional está na graduação é essencial.

Considerando a crescente necessidade de aprimoramento por parte dos profissionais que atuam no âmbito das Ciências Humanas e das Ciências Sociais Aplicadas para intervir e exercer suas atividades com pessoas surdas, torna-se relevante pesquisar sobre como está ocorrendo a formação destes profissionais nos cursos de graduação, se os conteúdos referentes à surdez, especificamente com relação à Libras, são trabalhados, de forma que o futuro profissional esteja apto e capacitado a atuar com esta situação em suas práticas, devido às mudanças sociais ocorridas, ao princípio da inclusão e à prestação de atendimento de qualidade à pessoa com deficiência auditiva.

Para isso, objetivou-se analisar as disciplinas das grades curriculares de três cursos destas áreas - Administração, Direito e Psicologia - e identificar se a temática da deficiência auditiva, especialmente em se tratando da Língua Brasileira de Sinais, está sendo abordada e, se estiver, de que maneira (como disciplina optativa ou obrigatória). Para tal faz-se necessário verificar o que a literatura tem apresentado sobre a luta dos sujeitos surdos e sobre a Libras, bem como sobre as competências dos profissionais da área das Ciências Humanas e Sociais Aplicadas.

Entende-se que esta pesquisa é de grande importância para o âmbito acadêmico, já que investiga as condições que as instituições de ensino superior dispõem ao aluno para que este se prepare adequadamente para lidar e atender satisfatoriamente pessoas com necessidades especiais, além de socialmente demonstrar a importância da reformulação das grades curriculares dos cursos de Ciências Humanas e de Ciências Sociais Aplicadas para que o aluno recém-formado adquira uma boa base sobre esta modalidade de 
http://dx.doi.org/10.5902/1984686X31472

necessidade especial, e contribua assim para atender às necessidades e exigências sociais que crescem mais a cada dia.

\section{Revisão da literatura}

Para que a sociedade atingisse o desenvolvimento ocorrido até hoje, houve a necessidade de uma interação, possibilitada pela linguagem. Assim, pode-se dizer que a linguagem tem papel fundamental na vida das pessoas, pois através dela expressamos sentimentos, transmitimos informações e ideias (SANTANA, 2013).

Da mesma maneira, os surdos também adotaram meios para sua comunicação, que ocorre através de movimentos gestuais e expressões faciais compreendidas por meio da visão - a Língua de Sinais. Esta é de suma importância para a inclusão social, pois além da comunicação também possibilita a interação desses sujeitos com a comunidade ouvinte (SANTANA, 2013).

Com base nos achados na literatura, observou-se, ao percorrer uma trajetória histórica, que os surdos foram considerados como seres "aleijados de linguagem", incapazes de aprender, de se comunicar e de se desenvolver (BENVENUTO, 2005 apud VIEIRA-MACHADO, 2010), tendo sido propagado que só poderia ser restituída a natureza humana aos surdos se estes aprendessem a língua oral (VIEIRA-MACHADO, 2010).

Mais tarde, realizaram-se práticas ortopédicas, trazendo a necessidade da formação de professores especializados. Porém, o surdo ainda era visto como um sujeito que necessitava de correção, ou seja, era necessária a cura do ouvido deficiente. No entanto, os sujeitos surdos foram resistentes, e persistiram com a Língua de Sinais (VIEIRAMACHADO, 2010).

Com a política de educação para todos desde 1994 em Salamanca, os surdos e a Língua de Sinais passam a fazer parte de discussões e seus saberes começam a ser valorizados, e, a partir disso, começou a ser repensado os saberes e as práticas dos professores (VIEIRA-MACHADO, 2010).

$\mathrm{Na}$ Declaração de Salamanca é abordada a questão dos direitos educacionais e linguísticos, afirmando que é necessário que as políticas educativas tenham em conta as diferenças individuais e as situações distintas, ou seja, deve ser reconhecida a importância da linguagem gestual como um meio de comunicação entre as pessoas surdas (DECLARAÇÃO DE SALAMANCA, 1994 apud YATIM; PEREIRA, 2016). Para isso, o 
conhecimento da Língua de Sinais tornou-se fundamental, principalmente quando foi sancionada em 2002 a Lei 10.436/02 de LIBRAS (VIEIRA-MACHADO, 2010).

Através da Lei Federal no 10.436 de 24 de abril de 2002 a Língua Brasileira de Sinais (Libras) foi reconhecida como a língua advinda das comunidades de pessoas surdas do Brasil, o que é um grande avanço no que diz respeito aos direitos dos surdos, caracterizando-se como uma conquista social e cultural. Com este reconhecimento legal, a LIBRAS é designada como uma entre as inúmeras línguas (LEMOS; CHAVES, 2012). De acordo com a legislação:

Entende-se como Língua Brasileira de Sinais - Libras, a forma de comunicação e expressão, em que o sistema linguístico de natureza visualmotora, com estrutura gramatical própria, constituem um sistema linguístico de transmissão de ideias e fatos, oriundos de comunidades de pessoas surdas do Brasil (BRASIL, 2002, s/p).

Já no Decreto 5.626/05 foi regulamentada a Lei de 2002, fazendo com que se tornasse obrigatório o ensino de Libras como disciplina nos cursos de licenciatura, magistério e fonoaudiologia, e como disciplina optativa nos demais cursos superiores (BRASIL, 2005 apud YATIM; PEREIRA, 2016).

Todavia, há a necessidade de expansão dessa disciplina para outras áreas, não apenas como uma disciplina optativa, pois ela é importante não só para o aprendizado da língua, mas também para a configuração de saberes sobre as especificidades culturais, linguísticas e de direito dos surdos. Além disso, pode contribuir para a exclusão de práticas que negam a língua de sinais, a inclusão do sujeito surdo, a medicalização e outros comportamentos, revertendo estas concepções (MARTINS; NASCIMENTO, 2014).

As áreas de Ciências Humanas e de Ciências Sociais Aplicadas são campos em que o conhecimento sobre a cultura e identidade surda, assim como da Língua Brasileira de Sinais, torna-se necessário devido ao estudo e contato com humanos e com aspectos sociais que permeiam a vida destes.

De acordo com a Tabela de Áreas do Conhecimento da Fundação CAPES, publicada em 31 de janeiro de 2017, os cursos escolhidos para compor os dados desta pesquisa encontram-se nas áreas de Ciências Humanas (Psicologia) e Ciências Sociais Aplicadas (Administração e Direito). No entanto, apesar desta classificação, pode-se dizer que também os cursos de Administração e Direito permeiam a área das Ciências Humanas, já que também trabalham com as relações humanas. 
http://dx.doi.org/10.5902/1984686X31472

Desta forma, no que diz respeito às Ciências Humanas, entende-se que estas são desafiadas no mundo moderno a propor caminhos viáveis às interrogações humanas e trazer esperanças, utilizando as vias científicas de validar suas descobertas. Seu estatuto científico tem um histórico marcado por controvérsias ideológicas e políticas acerca do conhecimento humano e do reconhecimento científico de sua contribuição à vida e à sociedade (CHIZZOTTI, 2016).

Já com relação às Ciências Sociais Aplicadas, pode-se dizer que estas têm o desafio de produzirem conhecimento reflexivo sobre as instituições e transformações sociais, além de contribuírem grandemente com o pensamento sobre as questões clássicas e emergentes, apontando caminhos às políticas. Também têm estudado as novas relações de trabalho, processos educacionais, formas de constituição das identidades coletivas e individuais, as desigualdades sociais, entre outros temas relevantes (SOBRAL, 2004).

No Curso de Graduação em Administração, o aluno deve ser capacitado a compreender questões cientificas, sociais e técnicas, apresentando flexibilidade intelectual e adaptabilidade em situações diversas, presentes ou emergentes, nos vários segmentos do campo de atuação do administrador, se expressando de maneira crítica perante os diferentes contextos sociais, ou seja, voltados ao lado humano. Assim, este curso baseiase nas organizações que são formadas por pessoas, envolvendo assim os agrupamentos humanos (BRASIL, 2005b).

De acordo com as Diretrizes Curriculares Nacionais do Curso de Graduação em Direito, este também está envolvido com as Ciências Sociais/Humanas, pois deve garantir uma formação geral, humanística e axiológica, interpretação de fenômenos sociais aliados a uma postura reflexiva e crítica, indispensável ao desenvolvimento da cidadania. Assim, o aluno é envolvido no curso de Direito com áreas do saber como Antropologia, Ciência Política, Economia, Ética, Filosofia, História, Psicologia e Sociologia, que devem ser estudados de maneira contextualizada com o ambiente cultural, econômico, social e político (BRASIL, 2004).

Já nas Diretrizes Curriculares Nacionais para o Curso de Graduação em Psicologia, ressalta-se que a meta é assegurar uma formação baseada em compreender os múltiplos referenciais que apreendem os fenômenos psicológicos em interface com fenômenos biológicos e sociais, reconhecer as perspectivas necessárias para compreensão do ser humano, ser capaz de compreender de maneira crítica os fenômenos sociais, culturais, que são fundamentais ao exercício da cidadania e da profissão, além de atuar em diferentes 
http://dx.doi.org/10.5902/1984686X31472

contextos, considerando as necessidades sociais e os direitos humanos, objetivando promover a qualidade de vida de sujeitos, grupos, organizações e comunidades (BRASIL, 2011).

É importante ressaltar que a Libras como disciplina possibilita o desenvolvimento linguístico, social e intelectual de seus usuários, sendo ampliada aos atendimentos públicos da sociedade como um estímulo à inserção dos surdos na sociedade, pois estes poderão exercer sua cidadania de maneira ativa e consciente no âmbito social, em razão de que sua língua será respeitada e reconhecida (ROSSI, 2011).

A inclusão de surdos é um tema que tem sido recorrentemente discutido, devido às barreiras de comunicação presentes na sociedade, decorrente da falta de conhecimento por parte dos ouvintes em relação aos surdos enquanto minoria linguística. Vários estudos realizados nesta área revelam que há uma difícil ligação entre os surdos, a língua oral e a sociedade ouvinte (GOLDFELD, 2002; STROBEL, 2009; GESSER, 2009 apud RIBEIRO; BIERNASKI, 2017).

Esta discussão torna-se importante devido à existência de uma grande parcela da população surda no Brasil. Em 2010, um censo do IBGE mostrou que há cerca de 9,7 milhões de brasileiros surdos, e, dessa forma, o conhecimento da língua de sinais torna-se fundamental, além da preservação dos direitos dos surdos (RIBEIRO; BIERNASKI, 2017).

A Libras configura-se como uma ferramenta necessária não somente para a comunicação dos sujeitos surdos, mas como uma conquista com vistas à inclusão desses sujeitos social e culturalmente. No entanto, mesmo com o reconhecimento através da Lei, ainda se reflete sobre a ausência da Libras em espaços públicos (LEMOS; CHAVES, 2012).

\section{Método}

De acordo com os objetivos a que este trabalho se propôs, foi utilizada a metodologia de pesquisa documental, de caráter qualitativo e quantitativo.

Levando isto em consideração, esta pesquisa em questão foi realizada em sites de Faculdades/Universidades públicas e privadas, através dos quais foram obtidas as matrizes curriculares dos 3 (três) cursos da área de Ciências Humanas/Sociais Aplicadas escolhidos (Administração, Direito e Psicologia). Além disso, foram utilizados artigos científicos encontrados em bases de dados eletrônicas e resoluções.

A coleta de dados foi realizada da seguinte maneira: através de pesquisa na internet buscou-se os sites de Faculdades/Universidades que ofertam os cursos escolhidos para 
http://dx.doi.org/10.5902/1984686X31472

compor os dados desta pesquisa, enfatizando as Faculdades/Universidades do Estado do Paraná, e excluindo as de caráter EAD - Educação à Distância.

Dessa forma, após o acesso aos sites, foram coletadas as matrizes curriculares dos cursos mencionados, sendo coletadas todas as matrizes encontradas. Alguns sites não disponibilizavam a opção "Matriz Curricular", então estes foram excluídos da pesquisa.

Ao total, foram encontradas e selecionadas: 25 (vinte e cinco) matrizes curriculares do curso de Administração; 23 (vinte e três) matrizes curriculares do curso de Direito; e 18 (dezoito) matrizes curriculares do curso de Psicologia. Feita a coleta, as matrizes curriculares encontradas foram lidas uma a uma na íntegra, buscando verificar se haviam disciplinas abordando a Língua Brasileira de Sinais - Libras.

Para analisar os dados obtidos através da leitura das grades curriculares, foi utilizada tanto a abordagem de pesquisa qualitativa, como a abordagem de pesquisa quantitativa. Após a verificação da existência ou não das disciplinas, objetivou-se estruturar uma tabela abordando itens como: cidade de oferta do curso, horas totais do curso, quantidade total de disciplinas, quantidade de disciplinas na área (Libras), nome das disciplinas na área, horas dessas disciplinas e, se caso for ofertada, informar se a disciplina é obrigatória ou optativa.

Além disso, também buscou-se realizar reflexões e relações entre os dados obtidos através da análise documental, intercalando com a literatura existente sobre o aspecto da formação de profissionais e a Língua Brasileira de Sinais, buscando assim verificar a confirmação ou refutação da hipótese inicial.

\section{Resultados}

A Tabela 1 expõe os dados obtidos através das matrizes curriculares dos cursos. Dessa maneira, foram analisadas 25 matrizes curriculares do curso de Administração, sendo que 12 destas abordam a disciplina de Libras em seus currículos e 13 não abordam essa disciplina. Além disso, dos 12 cursos mencionados, apenas uma instituição oferta a disciplina de Libras em caráter obrigatório, e as demais como optativa. Também é possível citar que 6 instituições mencionavam disciplinas optativas em seus currículos, mas não especificavam quais seriam essas disciplinas. A Tabela também apresenta os dados obtidos através das matrizes curriculares dos cursos de Direito. Foram coletadas 23 matrizes curriculares, sendo que a disciplina de Libras está presente em 9 destas, e 14 não ofertam a disciplina. Apenas 1 disciplina é ofertada como obrigatória, e as demais em caráter optativo. Além disso, 6 instituições não especificavam quais eram as disciplinas 
http://dx.doi.org/10.5902/1984686X31472

optativas disponíveis para escolha. Ainda, são retratados os dados obtidos através das matrizes curriculares dos cursos de Psicologia, tendo sido coletadas 18 matrizes. Dentre estas, 11 ofertam a disciplina de Libras e 7 não a mencionam em seus currículos, apenas mencionam a existência de disciplinas optativas, porém sem especificá-las. Das 11 instituições citadas, 2 contemplam essa disciplina em caráter obrigatório, porém em uma modalidade EAD.

Tabela 1 - Resultados das Matrizes Curriculares

\begin{tabular}{|c|c|c|c|c|c|c|}
\hline Curso & Cidade & $\begin{array}{l}\text { Horas } \\
\text { totais }\end{array}$ & $\begin{array}{l}\text { Discip. } \\
\text { totais }\end{array}$ & $\begin{array}{l}\text { Discip. } \\
\text { na área }\end{array}$ & $\begin{array}{l}\text { Soma horas } \\
\text { discip. na área }\end{array}$ & $\begin{array}{c}\text { Disciplina optativa ou } \\
\text { obrigatória }\end{array}$ \\
\hline \multirow{25}{*}{$\begin{array}{l}\text { Administra } \\
\text { ção }\end{array}$} & Araucária & 3600 & 43 & 1 & 80 & Optativa \\
\hline & Araucária & 3560 & 17 & - & - & - \\
\hline & Curitiba & 3108 & 48 & - & - & - \\
\hline & Curitiba & 3190 & 43 & 1 & 70 & Optativa \\
\hline & Curitiba & 3600 & 46 & 1 & $0^{1}$ & Obrigatória \\
\hline & Curitiba & 3680 & 38 & - & - & $\begin{array}{l}\text { Optativas não } \\
\text { informadas }\end{array}$ \\
\hline & Curitiba & 4044 & 48 & 1 & 80 & Optativa \\
\hline & Curitiba & 3480 & 49 & - & - & $\begin{array}{l}\text { Optativas não } \\
\text { informadas }\end{array}$ \\
\hline & Curitiba & 3040 & 48 & - & - & - \\
\hline & Curitiba & 3370 & 57 & - & - & $\begin{array}{l}\text { Optativas não } \\
\text { informadas }\end{array}$ \\
\hline & $\begin{array}{c}\text { Guarapuav } \\
\text { a }\end{array}$ & 3000 & 50 & 1 & - & Optativa \\
\hline & $\begin{array}{c}\text { Guarapuav } \\
\mathrm{a}\end{array}$ & 3106 & 56 & 1 & 36 & Optativa \\
\hline & Guaratuba & 3600 & 47 & 1 & 40 & Optativa \\
\hline & Ibaiti & 3000 & 49 & 1 & 40 & Optativa \\
\hline & Ivaiporã & 3040 & 52 & 1 & 60 & Optativa \\
\hline & Jacarezinho & 3000 & 34 & - & - & $\begin{array}{l}\text { Optativas não } \\
\text { informadas }\end{array}$ \\
\hline & Loanda & 3000 & 48 & 1 & - & Optativa \\
\hline & Londrina & 3000 & 51 & - & - & $\begin{array}{l}\text { Optativas não } \\
\text { informadas }\end{array}$ \\
\hline & Londrina & 3000 & 48 & 1 & - & Optativa \\
\hline & Maringá & 3600 & 47 & - & - & - \\
\hline & Maringá & - & 40 & - & - & - \\
\hline & Paranavaí & 3232 & 34 & - & - & - \\
\hline & $\begin{array}{c}\text { Pato } \\
\text { Branco }\end{array}$ & 3090 & 49 & 1 & - & Optativa \\
\hline & Pitanga & 3480 & 48 & - & - & $\begin{array}{l}\text { Optativas não } \\
\text { informadas }\end{array}$ \\
\hline & Rolândia & 2952 & 33 & - & - & - \\
\hline
\end{tabular}

${ }^{1}$ Consta na matriz curricular como sendo 0 (zero) o total de horas da disciplina de Língua Brasileira de Sinais. 
http://dx.doi.org/10.5902/1984686X31472

\begin{tabular}{|c|c|c|c|c|c|c|}
\hline \multirow{23}{*}{ Direito } & Araucária & 3496 & 60 & - & - & $\begin{array}{c}\text { Optativas não } \\
\text { informadas }\end{array}$ \\
\hline & Araucária & 4360 & 22 & 1 & 60 & Obrigatória \\
\hline & Curitiba & 4320 & 68 & 1 & 36 & Optativa \\
\hline & Curitiba & 4440 & 87 & 1 & 20 & Optativa \\
\hline & Curitiba & 3700 & 65 & - & - & - \\
\hline & Curitiba & 4920 & 37 & - & - & - \\
\hline & Curitiba & 5126 & 78 & 1 & 40 & Optativa \\
\hline & Curitiba & 4440 & 63 & - & - & - \\
\hline & Curitiba & 4310 & 65 & - & - & $\begin{array}{l}\text { Optativas não } \\
\text { informadas }\end{array}$ \\
\hline & Curitiba & 4080 & 66 & - & - & $\begin{array}{l}\text { Optativas não } \\
\text { informadas }\end{array}$ \\
\hline & $\begin{array}{l}\text { Foz do } \\
\text { Iguaçu }\end{array}$ & 4398 & 40 & - & - & $\begin{array}{c}\text { Optativas não } \\
\text { informadas }\end{array}$ \\
\hline & $\begin{array}{c}\text { Guarapuav } \\
\text { a }\end{array}$ & 4560 & 71 & 1 & 40 & Optativa \\
\hline & Guaratuba & 4580 & 68 & - & - & $\begin{array}{l}\text { Optativas não } \\
\text { informadas }\end{array}$ \\
\hline & Jacarezinho & 3830 & 40 & - & - & - \\
\hline & Londrina & 3530 & 41 & - & - & - \\
\hline & Maringá & 3780 & 61 & - & - & - \\
\hline & Maringá & - & 44 & - & - & - \\
\hline & Palmas & 3904 & 80 & 1 & 34 & Optativa \\
\hline & $\begin{array}{l}\text { Pato } \\
\text { Branco }\end{array}$ & 4280 & 70 & 1 & 40 & Optativa \\
\hline & Pitanga & 4400 & 68 & - & - & - \\
\hline & Rolândia & 3536 & 42 & - & - & - \\
\hline & Toledo & 4066 & 79 & 1 & 36 & Optativa \\
\hline & Umuarama & 4600 & 40 & 1 & 40 & Optativa \\
\hline \multirow{8}{*}{ Psicologia } & $\begin{array}{l}\text { Campo } \\
\text { Mourão }\end{array}$ & 4000 & 55 & - & - & $\begin{array}{l}\text { Optativas não } \\
\text { informadas }\end{array}$ \\
\hline & Cascavel & 4010 & 57 & 1 & 36 & Obrigatória (EAD) \\
\hline & Curitiba & 4040 & 65 & - & - & $\begin{array}{l}\text { Optativas não } \\
\text { informadas }\end{array}$ \\
\hline & Curitiba & 4004 & 68 & 1 & 36 & Optativa \\
\hline & Curitiba & 4036 & 77 & 1 & 36 & Optativa \\
\hline & Curitiba & 4000 & 46 & - & - & $\begin{array}{l}\text { Optativas não } \\
\text { informadas }\end{array}$ \\
\hline & Curitiba & 5310 & 62 & 1 & 80 & Optativa \\
\hline & Curitiba & 4040 & 71 & - & - & $\begin{array}{l}\text { Optativas não } \\
\text { informadas }\end{array}$ \\
\hline
\end{tabular}


http://dx.doi.org/10.5902/1984686X31472

\begin{tabular}{ccccccc}
\hline $\begin{array}{c}\text { Guarapuav } \\
\text { a }\end{array}$ & 4656 & 51 & - & - & $\begin{array}{c}\text { Optativas não } \\
\text { informadas }\end{array}$ \\
$\begin{array}{c}\text { Guarapuav } \\
\text { a }\end{array}$ & 4120 & 55 & 1 & 40 & Optativa \\
\hline Irati & 4176 & 46 & 1 & 68 & Optativa \\
\hline Londrina & 4000 & 95 & 1 & - & Optativa \\
\hline Maringá & 4000 & 70 & 1 & 40 & Obrigatória (EAD) \\
\hline Maringá & 4252 & 55 & 1 & - & Optativa \\
\hline Maringá & - & 51 & - & - & $\begin{array}{c}\text { Optativas não } \\
\text { informadas }\end{array}$ \\
\hline Maringá & 4200 & 52 & - & - & $\begin{array}{c}\text { Optativas não } \\
\text { informadas }\end{array}$ \\
\hline $\begin{array}{c}\text { Pato } \\
\text { Branco }\end{array}$ & 4138 & 62 & 1 & - & Optativa \\
\hline $\begin{array}{c}\text { Umuarama } \\
\text { Campo } \\
\text { Mourão }\end{array}$ & 4800 & 46 & 1 & 40 & Optativa \\
\hline
\end{tabular}

Fonte: Elaborada pelos autores.

\section{Análise e discussão}

Algumas matrizes curriculares dos cursos mencionavam a oferta de disciplinas optativas durante os semestres, porém não especificavam no documento quais seriam as opções disponíveis de disciplinas optativas para escolha. Dessa forma, totalizam 6 instituições para o curso de Administração, 6 instituições para o curso de Direito, e 7 instituições para o curso de Psicologia que não oferecem essa informação em suas matrizes curriculares. Além disso, foi observado nos resultados que, das 25 instituições que ofertam o curso de Administração, 13 instituições não mencionam a disciplina de Libras em seus currículos; das 23 instituições com o curso de Direito, 14 não ofertam esta disciplina; e das 18 instituições que possuem o curso de Psicologia, 7 delas não disponibilizam a disciplina.

Esses resultados mostram certo descaso destas instituições com as leis e diretrizes brasileiras sobre a inclusão social do surdo, pois, de acordo com o capítulo II do Decreto 5.626/05, fica definido que a Libras deveria ser inserida no currículo dos cursos de 
http://dx.doi.org/10.5902/1984686X31472

licenciatura, magistério e no curso de fonoaudiologia como disciplina obrigatória, além de se constituir como disciplina optativa nos demais cursos superiores e profissionais (BRASIL, 2005).

Esse descaso pode ser entendido a partir da interpretação de Gesser (2009), que entende que se dá muito mais importância ao discurso médico sobre a normalidade, assim, aqueles que não se encaixam no padrão da normalidade devem ser corrigidos. No entanto, espera-se que a comunidade acadêmica se afaste das noções de senso comum aplicadas a essas situações, dando espaço a uma noção crítica da realidade e como modificá-la de maneira a melhorar as relações.

Há a necessidade de considerar, também, que as instituições que oferecem o ensino superior, devem firmar compromisso com os objetivos da inclusão social, pois, uma vez que elas não estabelecerem esse compromisso, é mais provável que as matrizes dos seus cursos desconsiderem essas questões referentes à inclusão. De acordo com Mota (2014), existem casos em que o próprio surdo desconhece a existência da Libras, por isso é necessário que ela seja aceita e utilizada, não somente pelos surdos, mas por toda a sociedade.

Uma discrepância aparente no trabalho é apontada comparando-se as regiões consideradas mais e menos desenvolvidas do Paraná. Uma das regiões menos desenvolvidas do estado, a centro-sul, apresenta maior presença de Libras em suas grades (apenas um curso sem a disciplina), enquanto a região da capital, mais desenvolvida, é a que menos apresenta quantidade de disciplinas se comparada ao número de cursos (21 cursos e 12 não apresentam a disciplina). Uma pesquisa realizada por Ribeiro e Biernaski (2017) relata uma entrevista com uma pessoa surda que vive em Curitiba, mostrando que há dificuldades de inclusão desta pessoa em todas as esferas de sua vida, incluindo educação, saúde e campo de trabalho, e até mesmo dentro de sua própria família.

Outro ponto a ser destacado é a carga horária atribuída às disciplinas que abordam a Libras, pois, como foi possível perceber nos resultados, algumas instituições com cursos de cerca de 4 mil horas ofertam essa disciplina com uma carga horária baixa, sendo de 20 e 36 horas. A carga horária atribuída a essa disciplina não é suficiente para que se tenha excelência na aprendizagem da língua. É importante também considerar a metodologia, a avaliação e o uso de recursos utilizados no processo de ensino e aprendizagem de Libras nos cursos (LEMOS; CHAVES, 2012). 
http://dx.doi.org/10.5902/1984686X31472

É importante considerar a quantidade de horas destinadas à essas disciplinas porque a Libras não servirá apenas como um aspecto comunicacional entre surdos ou entre surdos e ouvintes, mas, por se tratar de uma língua, possui na sua configuração o constructo cultural desta comunidade. Desta forma o ideal é que seja entendida não somente a língua, mas a cultura da comunidade surda, dando vez a uma real inclusão social.

No Decreto 5.626/05, é ressaltado que o atendimento às pessoas surdas deve ser realizado por profissionais capacitados para o uso de Libras, para sua interpretação e tradução. Por isso, torna-se importante o questionamento quanto à natureza da disciplina de Libras ser optativa nos demais cursos de ensino superior. O caráter optativo desta disciplina quer dizer que não necessariamente ela será estudada, nem sempre será escolhida pela maioria como a disciplina optada para ser lecionada, pois seu caráter não garante que todos os profissionais obterão esse conhecimento, e, provavelmente, sairão da graduação com pouca ou nenhuma noção de atendimento e atenção às pessoas com surdez.

Esta demanda pode estar presente em qualquer ambiente, portanto, seria importante que os futuros profissionais de Administração, Direito e Psicologia recebessem um embasamento com relação à Libras ainda na graduação. Para Gesser (2009), as pessoas que têm contato com surdos devem aprender a Libras em vez de tentar outras alternativas de comunicação, evitando situações constrangedoras principalmente para o surdo.

Ainda de acordo com o Decreto 5.626/05, as instituições devem dispor de $5 \%$ de servidores capacitados para o uso da LIBRAS, sendo que o Poder Público, os órgãos da administração pública estadual, municipal e do Distrito Federal, e as empresas privadas devem buscar implementar essas medidas para assegurar tratamento diferenciado às pessoas surdas (BRASIL, 2005a). Com base nisso, se questiona se realmente há nas empresas, no âmbito público, da saúde, jurídico, entre outros órgãos de prestação de serviços, profissionais capacitados para atender à demanda das pessoas surdas, e se esta população recebe atendimento adequado, sendo efetivado realmente o propósito da inclusão em todas as esferas da vida social.

A falta de comunicação para com o surdo nos atendimentos causa barreiras de inclusão, além de prejudicar a qualidade do serviço ofertado, bem como o descumprimento das leis (RIBEIRO; BIERNASKI, 2017).

O reconhecimento da Libras como língua, bem como as leis de apoio ao surdo, abriu oportunidades para a inclusão destes sujeitos, causando impacto na sociedade de um 
http://dx.doi.org/10.5902/1984686X31472

modo geral (BARBOSA, 2011). Muitas conquistas já ocorreram para os surdos, porém, ainda existem limitações em várias esferas da sociedade. Dessa forma, é imprescindível que os profissionais estejam qualificados e determinados a modificar o conceito de exclusão (GODOI, 2009 apud ALVES; LEÃO; AGAPITO, 2017).

\section{Considerações finais}

Esta pesquisa centrou-se em investigar a presença da disciplina de Língua Brasileira de Sinais - LIBRAS - em cursos da área das Ciência Humanas e das Ciências Sociais Aplicadas, pois essas ciências dedicam-se ao estudo do homem como sujeito social, dessa maneira é imprescindível levar em conta o contexto social e histórico dos fatores humanos e sociais (DILTHEY, 1883 apud CHIZZOTTI, 2016). Essas ciências estiveram orientadas pelo estudo de fenômenos mediados pela linguagem, por relações intersubjetivas, sociais e econômicas (CZERESNIA, 2008).

A partir do que foi observado com a realização desta pesquisa, percebeu-se que, dentre os cursos estudados, o curso de Psicologia é o que mais aborda a temática da Libras, totalizando 11 instituições dentre as 18 selecionadas, sendo que as 7 instituições restantes não informavam quais eram as disciplinas optativas disponíveis para oferta, significando assim que há a possibilidade de que todas abordem esta disciplina, no entanto, em caráter optativo.

Através dos resultados obtidos por meio das matrizes curriculares dos cursos, foi possível confirmar a hipótese inicial de que a Libras não está sendo totalmente abordada como disciplina nos cursos da área de Ciências Humanas e Ciências Sociais Aplicadas, sendo significativo que este aspecto seja repensado pelas instituições, trazendo a necessidade de se repensar a formação destes profissionais, preocupando-se com as questões relacionadas à inclusão.

Entende-se que é necessário que a comunidade acadêmica se afaste de ideias reducionistas com relação à comunidade surda, repensando e articulando ações para que a inclusão possa atingir a todos os brasileiros.

Assim, é necessário que as instituições realizem avaliações periódicas sobre seus projetos pedagógicos e estruturas formativas, pois, de acordo com Silva (2009) é de grande importância que as universidades atuem cada vez mais próximas das necessidades que se apresentam na sociedade atual, preparando os formandos de maneira que estes venham a contribuir para a melhoria das relações humanas, do atendimento e atenção integral às 
http://dx.doi.org/10.5902/1984686X31472

pessoas, em destaque nesta pesquisa às pessoas com surdez, efetivando cada vez mais o princípio da inclusão para uma sociedade justa e igualitária.

A relevância em discutir essa questão está no fato de que, muitas vezes, a inclusão pode representar para alguns uma adversidade, já que surgem demandas que nem sempre esses profissionais conseguem responder, seja por falta de recursos ou por não estarem adequadamente capacitados para isso, sentindo-se, algumas vezes, sobrecarregados (LEVY E FACION, 2008 apud BARROS E OLIVEIRA, s/a).

Estima-se que esta pesquisa traga impactos educacionais no que diz respeito à formação de profissionais, pois pode contribuir para o melhor planejamento das matrizes curriculares de cursos da área das Ciências Humanas/Sociais Aplicadas, para que assim o profissional receba uma boa base sobre esta temática enquanto está na graduação, de maneira que a formação de profissionais aborde mais a Libras e leve em conta a luta dos sujeitos surdos para ganhar espaço na sociedade.

\section{Referências}

ALVES, Leandro Francisco; LEÃO, Marcelo Franco; AGAPITO, Francisca Melo. Políticas públicas voltadas para a inclusão social de surdos. Revista Destaques Acadêmicos. Lajeado, $\quad$ n. $2,2017 . \quad$ Disponível em: <http://www.univates.br/revistas/index.php/destaques/article/viewFile/1399/1156>. Acesso em 25 mai. 2018.

BARBOSA, Leonarlley Rodrigo Silva. A Língua Brasileira de Sinais como inclusão social dos surdos no sistema educacional. Polyphonía. Goiás, n. 2, jan/jun, 2011. Disponível em: <https://www.revistas.ufg.br/sv/article/download/21216/12444>. Acesso em 25 mai. 2018.

BARROS, Keila Rocha Santos; OLIVEIRA, Silmara Sartoreto Desafios e dificuldades na formação do professor diante de alunos com deficiência inseridos em salas regulares. S/a. In: MARTINS, Sandra Eli Sartoreto de Oliveira; GIROTO, Claudia Regina Mosca; SOUZA, Claudio Benedito Gomide. (Org.) Diferentes olhares sobre a inclusão. São Paulo: Cultura Acadêmica, 2013. $224 \quad$ p. 2 Disponível em: <https://www.marilia.unesp.br/Home/Publicacoes/af-livro_08_giroto.pdf>. Acesso em: 9 set. 2016.

BRASIL. Decreto no 5.626, de 22 de dezembro de 2005. Brasília, DF, 2005a.

BRASIL. Lei no 10.436, de 24 de Abril de 2002. Brasília, DF, 2002.

BRASIL. Resolução CNE/CES 9/2004. Diário Oficial da União, Brasília, Outubro de 2004, Seção 1, p. 17.

BRASIL. Resolução CNE/CES 4/2005. Diário Oficial da União, Brasília, Julho de 2005b, Seção 1, p. 26. 
http://dx.doi.org/10.5902/1984686X31472

BRASIL. CNE/CES 5/2011. Diário Oficial da União, Brasília, Março de 2011, Seção 1, p. 19.

CAPES. Tabela de Áreas de Conhecimento / Avaliação. 2017. Disponível em: <http://www.capes.gov.br/avaliacao/instrumentos-de-apoio/tabela-de-areas-doconhecimento-avaliacao>. Acesso em: 17 set. 2017.

CHIZZOTTI, Antonio. As ciências humanas e as ciências da educação. Revista ECurriculum. São Paulo, n. 4, out-dez. 2016. Disponível em: <https://revistas.pucsp.br/index.php/curriculum/article/view/30436>. Acesso em: 4 mai. 2017.

CZERESNIA, Dina. Epidemiologia, Ciências Humanas e Sociais e a integração das ciências. Revista Saúde Pública. São Paulo, n. 6, out. 2008. Disponível em: <http://www.scielo.br/scielo.php?script=sci_arttext\&pid=S0034-89102008000600020>. Acesso em: 4 mai. 2017.

GESSER, Audrei. LIBRAS? Que língua é essa?: Crenças e preconceitos em torno da língua de sinais e da realidade surda. São Paulo: Parábola, 2009.

GUARINELLO, Ana Cristina. et al. A disciplina de Libras no contexto de formação acadêmica em Fonoaudiologia. Revista CEFAC. São Paulo, n. 2, mar/abr. 2013. Disponível em: <http://www.scielo.br/pdf/rcefac/2012nahead/159-11.pdf>. Acesso em: 29 abr. 2017.

LEMOS, Andréa Michiles; CHAVES, Ernando Pinheiro. A disciplina de Libras no ensino superior: Da proposição à prática de ensino como segunda língua. XVI ENDIPE - Encontro Nacional de Didática e Práticas de Ensino - UNICAMP. Campinas, 2012.

MARTINS, Vanessa Regina de Oliveira; NASCIMENTO, Lilian Cristine Ribeiro. Algumas análises da disciplina de Libras nos cursos de licenciaturas: Reflexões e desdobramentos. Revista Intellectus. São Paulo, n. 30, nov. 2014. Disponível em: <http://www.revistaintellectus.com.br/DownloadArtigo.ashx?codigo=456>. Acesso em: 15 mai. 2017.

MOTA, Paola Rodrigues. Inclusão: o sujeito surdo na sociedade brasileira. Anais do I Congresso Internacional de educação e Inclusão - CINTEDI, Campina Grande - PB, 2014. Disponível em: <http://editorarealize.com.br/revistas/cintedi/trabalhos/Modalidade_1datahora_14_11_201 4_14_30_24_idinscrito_3102_fde1204a257fed075e3ed4c5f709b8ea.pdf>. Acesso ēm: 24 mai. $201 \overline{8}$.

RIBEIRO, Rafaella de Oliveira Canquerino; BIERNASKI, Simone do Rocio. Aspectos da comunicação do sujeito surdo e sua inclusão na sociedade. Anais do EDUCERE - XIII Congresso Nacional de Educação - VI Seminário Internacional sobre Profissionalização Docente - SIPD/CÁTEDRA UNESCO. Curitiba, 2017. Disponível em: <http://educere.bruc.com.br/arquivo/pdf2017/25417 13281.pdf >. Acesso em 24 mai. 2018.

ROSSI, Renata. Aparecida. A Libras como disciplina no Ensino Superior. Revista de Educação. São Paulo, n. 15, out, 2011. Disponível em: 
<http://www.pgsskroton.com.br/seer/index.php/educ/article/viewFile/1867/1772>. Acesso em 26 abr. 2017.

SANTANA, Eline. Peixoto. O Direito e a comunicação: as Libras e os desafios da educação dos surdos. VI Jornada Internacional de Políticas Públicas. 2013, São Luís do Maranhão, Anais. São Luís do Maranhão, 2013. Disponível em: <http://www.joinpp.ufma.br/jornadas/joinpp2013/JornadaEixo2013/anais-eixo8-

direitosepoliticaspublicas/odireitoacomunicacao-

asLibraseosdesafiosdaeducacaodossurdos.pdf>. Acesso em: 27 abr. 2017.

SANTOS, Jonas; ASSIS, Monique Ribeiro. As dificuldades do psicólogo no atendimento à pessoa com deficiência auditiva. Conexões Psi. Rio de Janeiro, n. 1, jan/jun. 2015. Disponível em: <http://apl.unisuam.edu.br/revistas/index.php/conexoespsi/article/download/616/548>Aces so em: 27 abr. 2017.

SILVA, Eliana. Formação de professores em educação especial: a experiência da UNESP - Campus de Marília - SP. 2009. 117 f. Dissertação (Pós-Graduação em Educação) Faculdade de Filosofia e Ciências da Universidade Estadual Paulista - UNESP, Marília, São Paulo, 2009.

SILVA, Lidia Martins. Educação inclusiva e formação de professores. 2009. 90 f. Monografia (Pós-Graduação em Educação Profissional Tecnológica Inclusiva) - Instituto Federal de Educação, Ciência e Tecnologia do Estado do Mato Grosso, Cuiabá, Mato Grosso, 2009.

SOARES, Carlos Henrique Ramos. A implementação da disciplina de Libras no ensino superior: questões para reflexão. X ANPED Sul, Florianópolis, 2014. Disponível em: <http://xanpedsul.faed.udesc.br/arq_pdf/442-0.pdf>. Acesso em: 26 abr. 2017.

SOBRAL, Fernanda. Desafios das Ciências Sociais no desenvolvimento científico e tecnológico contemporâneo. Sociologias. Porto Alegre, n. 11, jan/jun. 2004. Disponível em: <http://www.scielo.br/pdf/soc/n11/n11a10.pdf>. Acesso em: 11 out. 2017.

VIEIRA-MACHADO, Lucyenne Matos da Costa. Formação de professores de surdos: dispositivos para garantir práticas discursivas. Cadernos de Educação, FaE/PPGE/UFPel. Pelotas, n. 36, mai/ago. 2010. Disponível em: <https://periodicos.ufpel.edu.br/ojs2/index.php/caduc/article/view/1600/1483>. Acesso em: 21 abr. 2017.

YATIM, Nahla; PEREIRA, Janaí de Abreu. A aprendizagem de Libras como L2 no ensino superior. Centro Virtual de Cultura Surda. Revista Virtual de Cultura Surda. Rio de Janeiro, n. 18, jul. 2016. Disponível em:<http://editora-araraazul.com.br/site/admin/ckfinder/userfiles/files/Artigo\%202\%20YATIM\%20\%26\%20PEREIR A.pdf>. Acesso em: 26 abr. 2017. 


\section{Correspondência}

Weslley Kozlik Silva - Universidade Federal do Paraná, Rua XV de Novembro, 1299 - Centro. CEP: 80060-000. Curitiba, Brasil. http://orcid.org/0000-0002-1825-0097

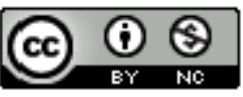

This work is licensed under a Creative Commons Attribution-NonCommercial 4.0 International (CC BY-NC 4.0) 